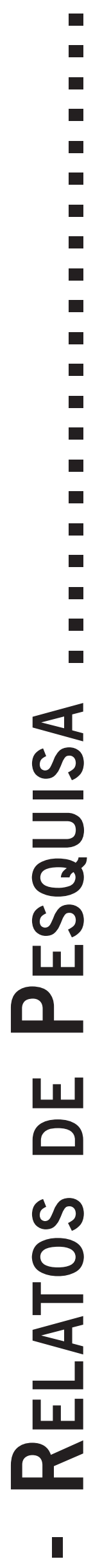




\title{
"TEM QUE NASCER JÁ COM AQUELE DOM": VIVÊNCIAS DE UMA JOVEM TRAVESTI
}

\author{
"You have to be born with that gift": Experiences of a Young Travesti
}

"Tiene que haber nacido con ese don": Experiencias de un Joven Travesti

\author{
RoBerta NORONHA AZEvedo \\ FABIO SCORSOLINI-COMIN \\ GIANCARLO SPIZZIRRI
}

\begin{abstract}
Resumo: O objetivo deste estudo de caso foi conhecer as vivências sociais, afetivas e sexuais de uma jovem travesti e compreender sua percepção sobre a identidade de gênero. Utilizou-se uma entrevista semiestruturada. A análise deu-se a partir do referencial fenomenológico. A participante possui 22 anos, atua como profissional do sexo e diz não se sentir como um homem ou uma mulher, mas uma travesti. No que tange ao seu "mundo próprio", nota-se que a entrevistada evita e foge da angústia, o que dificulta que se conscientize de seus sentimentos e diminua sua capacidade para fazer integração existencial de suas escolhas. Isso parece impedi-la de assumir e de transformar seu "mundo próprio", mantendo pensamentos, sentimentos e condutas rígidos e com pouca mobilidade. O olhar do pesquisador deve ser o de acolher essa escuta e compreendê-la, com destaque para a potencialização de seus recursos.
\end{abstract}

Palavras-chave: Identidade de gênero; Travestismo; Estudos de casos.

Abstract: The aim of this case study was to understand the social, emotional and sexual experiences of a young travesti and understand their perception of gender identity. We used a semistructured interview. The analysis was conducted from the phenomenological method. The participant has 22 years, acting as a sex worker and says not feel like a man or a woman, but a travesti. In terms of their "own world", there is evidence that has a lesser degree self-awareness, with less integrated existential choices. This seems to prevent her from taking over and transforming their "own world", keeping thoughts, feelings and behaviors and rigid with little mobility. The researcher should be to accommodate this listening and understand it, especially the enhancement of its resources.

Keywords: Gender identity; Transvestism; Case studies.

Resumen: El objetivo de este estudio fue conocer las experiencias sociales, emocionales y sexuales de una joven travesti y comprender su percepción de la identidad de género. Se utilizó una entrevista semiestructurada. Se realizó un análisis fenomenológico. La participante tiene 22 años, actúa como prostituta y dice que no se siente como un hombre o una mujer, sino un travesti. En su "propio mundo" hay evidencia de que tiene un menor grado de auto-conciencia, con opciones existenciales menos integrados. Esto parece evitar que se apoderen y transformar su "propio mundo", manteniendo pensamientos, sentimientos y comportamientos rígidos y con poca movilidad. La mirada del investigador debe ser para dar cabida a esta escucha y lo entiendo, sobre todo el aumento de sus recursos.

Palabras clave: Identidad de género; El travestismo; Los estudios de caso.

\section{Introdução}

Tema que aguça interesse por parte de leigos e especialistas, nos últimos anos, a sexualidade tem sido objeto privilegiado do olhar de pesquisadores e profissionais de diversas áreas. Ao longo dos séculos, foi descrita, compreendida, educada, controlada e normatizada de muitas formas (Louro, 2001), oferecendo maior ou menor espaço para recriações e pluralidades que hoje constituem de modo definitivo o campo da sexualidade e a complexidade que atravessa a pesquisa empírica na área, bem como a atuação profissional quando são trazidas à baila expressões como queer, práticas sexuais, movimentos LGBT (lésbicas, gays, bissexuais, travestis, transexuais e trans- gêneros), homofobia, transfobia, orientações e identidades, por exemplo. Em uma seara cada vez mais marcada pelo trânsito no modo de se definir, expor, questionar e explicar a sexualidade, estudos que elenquem a população LGBT como foco têm se ampliado tanto como forma de promover a visibilidade desses sujeitos na ciência quanto de compreender suas vivências, particularidades e necessidades, em um paradigma que busca superar binarismos e modos estereotipados e preconceituosos de abordar o humano.

Dentro deste tema, na atualidade, destacam-se as reflexões relacionadas à identidade de gênero dos seres humanos. Com características que confrontam a noção de gênero vigente socialmente estão os travestis e os transe- 
xuais. No presente estudo, focalizaremos indivíduos travestis, que são aqueles que se identificam com as imagens de gênero contrários ao seu sexo biológico e utilizam vestimentas e adornos do gênero desejado, podendo ou não fazer uso de próteses e hormônios para a transformação de seus corpos, mas que não têm o desejo de se submeterem a cirurgias de redesignação sexual (Chidiac \& Oltramari, 2004; Pelúcio, 2005; Araújo Júnior, 2006; Moraes, 2009; Peres, 2009; Peres \& Toledo, 2011; Galli, 2013)

De acordo com Amaral, Silva, Cruz e Toneli (2014), ainda é recente o movimento da ciência brasileira em torno das categorias "travestis", "travestismo" e "travestilidades", sendo que os primeiros estudos são datados da década de 1990, utilizando metodologias típicas das ciências sociais, como etnografias em espaços frequentados por essa população. A maior parte dos estudos sobre os travestis concentra-se em aspectos relacionados à sua saúde física e psicológica (Spizzirri, Azevedo \& Abdo, 2011; Galli, 2013). Em sua maioria, tencionam verificar o uso de preservativos, o consumo de álcool e substâncias psicoativas, incidência de doenças sexualmente transmissíveis, traços de personalidade e a presença de transtornos mentais. Poucos estudos investigam as características psicossociais e subjetivas dos travestis e um número ainda menor busca fazê-lo utilizando metodologia qualitativa (Azevedo, 2009; Leite Jr, 2011; Duque, 2012; Azevedo, Spizzirri, \& Scorsolini-Comin, 2014)

Dentro da temática específica da identidade de gênero, estudos recentes na área da ciência social têm questionado a noção de gênero vigente e destacam que as fórmulas pautadas no binômio masculino versus feminino não são válidas frente à realidade da diversidade das identidades de gênero com que nos defrontamos cotidianamente (Miskolci \& Pelúcio, 2007; Peres, 2012) e são insuficientes para explicar a complexidade com que a sexualidade se apresenta. Desse modo, trabalham com a noção de uma desnaturalização do gênero. Este é visto não como algo que determine um sentido em si do sujeito, mas sim como expressões ou efeitos que fazem parte de sua identidade e, por conseguinte, da sua sexualidade e também do modo como constrói a sua subjetividade (Louro, 2001; Butler, 2002). Seguindo este raciocínio, homossexuais, bissexuais, travestis, transgêneros, drag queens, transexuais, entre outros, provocam questionamentos sobre os enquadramentos e as regras produzidos por discursos normatizadores (Louro, 2001).

Na literatura científica, as experiências travestis têm sido abordadas a partir de temas como aids, transformação corporal e prostituição, sendo poucos os estudos referentes ao envelhecimento, adolescência e educação, elementos que podem ser norteadores de políticas públicas, por exemplo, relacionadas à violência sofrida pelas travestis, suas condições de vida e saúde (Amaral et al., 2014). Dada a escassez de investigações que busquem conhecer as experiências vividas por essa população, este estudo de caso pretende contribuir nesta direção por meio de uma aproximação qualitativa, utilizando-se da abordagem fenomenológica, das experiências de uma travesti, objetivando conhecer de que maneira significa suas vivências sociais, afetivas e sexuais e, principalmente, compreender qual a percepção que tem sobre sua identidade de gênero. A questão que norteou o estudo foi: de que modo uma travesti compreende as suas vivências pessoais ao longo do ciclo vital relacionadas à construção da identidade de gênero?

\section{Método}

\subsection{Tipo de estudo}

Trata-se de um estudo de caso de corte transversal, fundamentado na abordagem qualitativa e no método fenomenológico, especificamente na proposta da Psicologia Fenomenológica (Forghieri, 1993). Nesse tipo de estudo existe uma limitação na extensão da casuística investigada, mas tal estratégia favorece uma abordagem em profundidade do fenômeno focalizado, com ênfase na constituição da subjetividade humana (Peres \& Santos, 2005). O estudo de caso foi priorizado como forma de nos aproximar das vivências do sujeito focal e ter acesso a especificidades de suas vivências, a partir de um relato exaustivo, detalhado e reflexivo do modo de existir da participante. Este caso sustenta-se nas particularidades da travesti escolhida, de modo que suas considerações devem ser relativizadas em termos de alcance, mas ampliadas no sentido de acessar experiências que, de outro modo, não poderiam ser compreendidas nem recuperadas a partir de outros delineamentos metodológicos.

\subsection{Participante}

O critério para participar do estudo era ser travesti (apresentar-se como travesti), possuir menos de 25 anos de idade (a fim de enquadrá-la na categoria de adulto jovem) e atuar como prostituta, como forma de acessar tanto as suas práticas profissionais como ampliar a possibilidade de acesso à participante. Neste estudo, a voluntária foi chamada de Ketlen (nome fictício), possui 22 anos de idade, é solteira, ensino superior incompleto e atua como profissional do sexo em uma cidade do interior do Estado de São Paulo.

\subsection{Instrumento}

Para a realização da entrevista empregou-se um roteiro semiestruturado desenvolvido pelos pesquisadores, que contemplou os temas da identidade de gênero e relacionamentos afetivos e sociais. As perguntas ocorreram de forma aberta para propiciar liberdade de respostas, con- 
tribuindo na percepção de suas atitudes e valores. Como se trata de uma pesquisa fenomenológica, cuidou-se para que as perguntas não restringissem muito o repertório de possibilidades de acesso às experiências narradas. Assim, a pergunta que norteou a entrevista foi: como é a sua vivência como travesti? A partir das narrativas trazidas em resposta a essa questão, outras perguntas foram sendo apresentadas pela entrevistadora no momento da entrevista, a fim de abarcar uma ampla gama de experiências em diferentes áreas da vida e ao longo de todo o ciclo vital, compreendendo a construção de gênero como algo que ocorre constantemente. Desse modo, as perguntas buscaram abarcar os movimentos e os processos de transformação, em contraposição a definições prontas e estáticas acerca das vivências da travesti.

\subsection{Procedimento}

Coleta de dados. O primeiro contato com a participante deu-se por telefone, a partir de recrutamento pela rede de contatos dos pesquisadores. A entrevista audiogravada ocorreu na residência da voluntária e durou três horas, sendo posteriormente transcrita na íntegra e literalmente e compondo o corpus da investigação. No que tange aos cuidados éticos, a pesquisadora manteve uma postura de cuidado e respeito ao fazer um contato que respeitasse a liberdade e a capacidade de tomada de decisão da entrevistada, garantiu que dados de identificação não seriam revelados, que poderia interromper a entrevista a qualquer momento e se prontificou a dar suporte psicológico à participante caso esta sentisse necessidade. As condições do estudo estavam presentes no Termo de Consentimento Livre e Esclarecido, lido, discutido e assinado por ambas as partes (participante e pesquisadora). Este estudo faz parte de uma investigação mais ampla, aprovada pelo Comitê de Ética em Pesquisa da instituição de origem do terceiro autor (Protocolo CEP 2162/2012).

Análise dos dados. Após transcrição e leitura exaustiva do material, foram construídos eixos temáticos para a compreensão das experiências da participante nas diferentes dimensões do existir. Esses eixos foram construídos a partir das falas da participante, compondo seis núcleos de experiências: (a) Vivências no cotidiano escolar; (b) Vivências afetivas; (c) Questões relacionadas à identidade de gênero; (d) Vivências sociais; (e) Vivências de sua atividade sexual; (f) Saúde física e psíquica. A análise desses núcleos foi empreendida pelo referencial teórico e metodológico da fenomenologia. A fenomenologia, cujos principais proponentes são Husserl e Heidegger, surgiu no campo da filosofia como uma reação ao positivismo que considerava válido somente os fenômenos pesquisados empiricamente, abordagem apropriada, portanto, para os trabalhos de Ciência Natural, mas insuficiente para a compreensão dos fenômenos humanos (Dartigues, 2005).
Assim, a fenomenologia surge como um método que possibilitaria ao pesquisador chegar à essência do conhecimento humano (Forghieri, 1993).

A investigação fenomenológica parte do entrelaçamento e da integração entre objetividade e subjetividade. $\mathrm{O}$ cientista não fica preso à busca da objetividade, de um mundo que existe independente do sujeito e tampouco à subjetividade de uma realidade interior alheia ao mundo (Augras, 1986). A realidade é vista sempre como realidade percebida (Sapienza, 2008). O procedimento essencial do pesquisador que utiliza a fenomenologia é chamada de redução fenomenológica. Nesta redução, o pesquisador procura manter fora de seu campo perceptivo seu conhecimento prévio a respeito do tema e procura penetrar e partilhar da situação vivenciada por outra pessoa (presencialmente ou por meio de relatos), a fim de poder compreender como ela vivencia aquela situação de acordo com seu próprio modo de existir (Forghieri, 1993).

Sobre o método fenomenológico, Augras (1986) afirma que a construção do mundo pelo ser humano é feita por meio da elaboração de significados e que a investigação pretende identificar estruturas significativas, a partir da observação das imagens elaboradas pela vivência cotidiana. Assim, o método fenomenológico procura essencialmente descrever, explicitar a chamada percepção categorial das pessoas, ou seja, o modo peculiar que têm de ser-no-mundo ou de captar os objetos, as pessoas e as situações (Forghieri, 1984). Parte-se do princípio de que "as descrições feitas pelos sujeitos são a melhor forma de se ter acesso a seu mundo-vida” (Martins \& Bicudo, 2005, p. 98). Diferentemente das pesquisas das Ciências Naturais que buscam a explicação dos fenômenos, a fenomenologia busca sua compreensão (Dartigues, 2005).

\section{Resultados}

Ketlen passou sua infância em uma metrópole na região nordeste do Brasil. Morava com sua mãe, seu pai e dois irmãos, sendo um mais velho e outro mais novo. A situação socioeconômica da família era precária. Nos fundos da casa morava sua avó materna. Apresenta-se como uma criança que gostava de ficar em casa, com poucos amigos e que não gostava de brincar. Seu pai fazia uso abusivo de álcool e, especialmente aos finais de semana, agredia sua mãe, física e verbalmente. Quando os finais de semana se aproximavam, ficava apreensiva aguardando a volta do pai. Sentia-se impotente perante o problema e utilizava o recurso de chamar a polícia para proteger sua mãe. Com esta o relacionamento sempre foi próximo e afetuoso. Depreende-se das falas da entrevistada que desde sua infância, a mãe, frágil para enfrentar seus problemas, buscava proteção em Ketlen. O movimento de proteger sua mãe parece ter se perpetuado em sua vida. Atualmente, envia uma quantia mensal em dinheiro para a mãe e comprou uma casa para ela morar. 
Ketlen percebe o relacionamento com o pai como distante. Relata que atualmente tem pouco contato com ele e quando o faz é para poder resolver problemas protagonizados por ele. Acredita que o pai tenha medo de suas críticas. Com o irmão mais velho a relação também é distante. Segundo a entrevistada, ele se parece muito com o pai e é agressivo com sua mãe. Em função disso, preferiu afastar-se. Já com o irmão mais novo, de 12 anos, Ketlen tem uma relação próxima e afetuosa. Com os tios e primos, parece ter se aproximado mais após sua adolescência. Relata ter bom relacionamento com todos. Tem um vínculo mais próximo com a família do pai, especialmente uma de suas tias e suas primas e primos.

\section{Vivências no cotidiano escolar}

O período escolar, especialmente até a $5^{\mathrm{a}}$ série do Ensino Fundamental, foi bastante difícil, sofreu muitos episódios de bullying perpetrados pelos colegas. Como estratégia para enfrentar o problema, procurava ficar perto do segurança da escola ou da diretoria para evitar que os colegas se aproximassem, ela comenta:

...Na escola era difícil. Era difícil. (...) Era difícil porque me chamavam de... (...) Veadinho, goiabinha... um punhado de coisa, né. (...), olha ali o veadinho, não sei o que..., sabe? Porque eu era assim toda meio mole, meio quebrado... já dava pra perceber assim que eu era afeminada... (...) Às vezes eu não queria ir pra escola... mas eu não deixava aquilo me levar, né. (...) Eu ficava triste... eu chorava. No intervalo eu sempre procurava ficar perto da diretoria sabe... do segurança da escola. Eu não ficava com ninguém... (...) Eu não entendia o porquê que eles estavam fazendo aquilo. Por quê? Por que estavam fazendo aquilo comigo. Eu não conseguia entender, ainda...

A conduta da escola frente ao problema era a de aplicar punição aos colegas que a intimidavam, o que melhorava momentaneamente a importunação, mas não resolvia a situação. Ketlen relata que havia alguns colegas que também tinham trejeitos efeminados e eram discriminados e que acabou estabelecendo maior amizade com estes. Aos poucos, afirma que a situação na escola foi melhorando; acredita que pelo fato de ter estudado na mesma instituição até o Ensino Médio, os colegas foram aprendendo a conviver com sua presença sem se incomodar tanto. A percepção de Ketlen é corroborada pelo estudo de Ceglian e Lyons (2004), que investigou o grau de desconforto em relação aos travestis em um meio universitário, antes e após um período de interação com os mesmos. Os autores apontam para a diminuição do grau de desconforto e preconceito em relação a travestis após um tempo de convivência com os colegas. Em termos das vivências no âmbito da escola, retomam-se as considerações de Peres
(2009) acerca da diversidade sexual nesse contexto, que coloca em xeque uma discriminação que não começa nesse ambiente necessariamente, mas carrega dificuldades trazidas pela criança desde a família. Ao entrar na escola, a criança já possui um repertório de discriminação, o que pode se potencializar nesse ambiente de socialização se não forem adotadas práticas adequadas e se não houver a discussão sobre diversidade sexual envolvendo toda a comunidade escolar.

\section{Vivências afetivas}

Ketlen teve somente um relacionamento amoroso que considera importante. Namorou esse rapaz durante três anos e meio enquanto morou em São Paulo; ele era casado e tinha três filhos. No entanto, esse fato nunca o impediu de dar atenção a ela, passear e viajar. Relata que ele a assumia para os amigos e para sua mãe, que não aprovava a relação. O relacionamento é apresentado como muito importante para ela, haja vista que eram muito companheiros, ajudavam-se mutuamente e gostavam um do outro:

E era assim, na hora que precisasse dele, ele tava ali, perto de mim... cada vez que... se eu ligasse ele vinha de onde ele estivesse. E era gostoso. A gente se via praticamente todos os dias (...) Porque eu era doente por ele. Nossa! Eu era doente. (...) Da minha parte eu acho que era amor. Da parte dele eu acho que era um gostar, um carinho, sei lá. (...) Eu dava muito carinho pra ele, conversava com ele, compreendia ele. Ah, ele falava que me amava.

Embora Ketlen sentisse que o amava, não expressava esse sentimento verbalmente para o namorado por medo de que, ao sentir-se seguro, ele passasse a desvalorizá-la. No terceiro ano de namoro, soube que quando fora visitar sua família e ficara alguns dias longe de São Paulo, seu namorado deu atenção para outras travestis e foi a um bar com elas. Esse fato marcou o início de um período de desconfiança e desentendimentos no relacionamento. Ketlen passou a não confiar mais nele e sentia muito ciúme. Em seguida ficou sabendo por uma amiga que ele havia "ficado" com outra travesti. Nesse dia, a entrevistada refere que bebeu, descontrolou-se e chegou a atirar um copo no rosto do namorado, ferindo-o. Ficaram separados por algum tempo e narra ter sentido muita falta dele. Resolveram, então, reatar o relacionamento. No entanto, após esse retorno, não se sentia tão bem quanto antes, não conseguia confiar nele. Após alguns meses resolveu terminar definitivamente o namoro.

Aí eu fiquei sabendo que ele tinha ficado com uma pessoa. Aí eu nervosa, comecei a beber. Beber, beber, beber... (...) Aí eu fiquei nervosa porque eu fico nervosa muito rápido, tomo muito hormônio... aí eu joguei 
um copo assim na cara dele... um copo que tinha lá, aí cortou assim... a testa dele. (...) Aí nesse período que a gente ficou separado, eu sofri horrores. Eu chorava todo dia, senti falta dele. Sabe por que eu senti a falta dele? Porque eu sabia: "Gente, eu nunca vou encontrar homem igual”. (...) O modo como ele me tratava. Não tinha vergonha, me assumia, sabe. (...) Aí a gente voltou. Aí sabe, eu comecei a ver que eu não era a mesma. (...) Mudou completamente... eu não confiava mais. Eu não confiava mais. (...) até que eu cheguei pra ele e falei. (...) Nossa, pra criar coragem pra terminar com ele, foi difícil. (...) Eu preferi terminar, eu senti falta dele, sabe... eu sentia muita falta dele, no começo foi difícil.

Ketlen relata que não deseja estabelecer novos relacionamentos amorosos. Sente que se envolve demais e isso a afeta emocionalmente, prejudicando sua vida. No entanto, sente falta do companheirismo, da parceria e do carinho proporcionados por um relacionamento afetivo. Desse modo, a sua afetividade pode ser compreendida dentro de uma lógica normatizadora e heteronormativa (Louro, 2009) segundo a qual ela não pode ser uma travesti, mas deve ser uma mulher e comportar-se como uma na passividade, na vestimenta e no comportamento social que prevê que o feminino se entregue mais na relação, cuide, agrade e seja romântico. Cumpre observar que essa lógica também é a que a entrevistada segue, significando relacionamentos afetivos com um ideal romântico, de pares "perfeitos" em que o binômio masculinidade e feminilidade assumem papéis bem definidos, rígidos, opostos e complementares. A dificuldade de estabelecer um relacionamento amoroso com um homem pode ser ilustrada com o medo de não mais conseguir encontrar um namorado que a assuma socialmente. Ainda assim, esse homem possui uma vida dupla, é casado e possui filhos, sendo que a afetividade de Ketlen parece ter que se ajustar às circunstâncias e ao que ela "consegue" encontrar, e não uma relação amorosa que atenda às suas necessidades e desejos. A vivência marginal desse relacionamento também aponta para uma afetividade com referências ao universo heteronormativo.

\section{Questões relacionadas à identidade de gênero}

Quando criança, Ketlen não gostava de brincar com os colegas, não tinha muitos amigos e as brincadeiras típicas dos meninos eram as que menos gostava, como jogar bola, nadar no rio, soltar pipa e correr. Entretanto, afirma que também não brincava de brincadeiras típicas femininas como casinha, boneca, professora, dentre outras. Durante a infância sua vida se restringia aos estudos e à permanência em casa. A única brincadeira que se lembra de participar era um jogo de lápis e papel que fazia com as meninas da escola.
Seu comportamento de travestir-se se iniciou na infância, haja vista que sempre teve vontade de se vestir de mulher e que quando estava sozinha em casa colocava uma toalha na cabeça e passava esmalte nas unhas. Sempre desejou ir além desses comportamentos, vestindo-se e maquiando-se como mulher, mas não o fazia com medo de represálias, como afirmava:

Me travesti de mulher? (silêncio) Eu sempre tive vontade, sempre. Sempre tive... muita vontade. (...) Sempre... desde criança. Quando a minha mãe saía que eu ficava sozinha, eu colocava toalha na cabeça... (...) eu pintava minha unha de base... e ficava... pegava o esmalte da minha mãe e ficava...

A primeira vez que se travestiu por completo foi no teatro da escola, situação na qual podia usar vestimentas femininas sem ser criticada. Sente que desde criança acreditava ser homossexual, mas foi a partir dos 11 anos, quando passou a participar de brincadeiras sexuais com o primo, que começou a entender o que isso significava:

(...) desde criança eu já sabia que eu era um gay, um homossexual. (...) Eu consegui me entender depois dos meus 11 anos. Com os meus 11 anos eu comecei a entender, né... "por que eu sou assim?” Eu era diferente dos outros... dos outros meninos. (...) As brincadeiras com os meus primos, sabe? (...) É... troca-troca... porque eu, com 12 anos eu já... já sabia, já tinha relação sexual com o meu primo.(...) Tudo, tudo eu achava gostoso.

Entre os 12 e os 14 anos, quando ia à casa do primo aos finais de semana, participava de experiências sexuais, essas ocorriam somente com este primo e perduraram por dois anos. Quando questionada sobre esse envolvimento, afirma que não havia afetividade, que a motivação era para realizar práticas sexuais. Nessa fase, durante os finais de semana em que ficava na casa de sua tia, Ketlen relata que sua prima a travestia e lá se sentia à vontade para expressar sua feminilidade.

Aos 15 anos, iniciou um namoro com uma garota. Esse relacionamento durou um ano e meio e chegaram a morar juntos na casa de sua mãe, devido ao fato da namorada ter engravidado. Iniciou essa relação com a intenção de se aproximar da heterossexualidade, mas não se sentia bem. Quando questionada sobre como se percebia ao ter atividade sexual a namorada, Ketlen relata que não lhe causava sofrimento, mas que não tinha atração sexual. Com poucos meses de gravidez, sua namorada perdeu o bebê e, então, Ketlen resolveu assumir a homossexualidade para sua mãe e sua família. Conta que ao mesmo tempo em que namorava essa garota, mantinha um relacionamento com um menino. Comenta:

...E eu ia sendo pai e tudo, mas graças a Deus... Deus sabe o que faz, né... e ela tinha o útero infantil e perdeu. 
Aí, depois que ela perdeu foi a minha oportunidade. Aí eu cheguei pra minha mãe e contei pra ela que eu não era feliz com ela, que eu era feliz de outro jeito... Apesar que nos meus 15 anos pra 16 eu já tinha um namoradinho, né... que eu saía as escondidas. Aí eu falei pra ela...

Deve-se ressaltar que na família paterna de Ketlen há dois primos homossexuais e uma prima travesti, portanto ela tinha referência sobre a travestilidade. Sua prima, além disso, constituiu um exemplo a ser seguido. A entrevistada relata que se sentia muito bem quando estava com eles e que tinha fascínio pela transformação física dessa prima, que mora no exterior, chegando a desejar ser como ela. Aos 16 anos, Ketlen sentiu a necessidade de feminilizar seu corpo e iniciou a ingestão de pílulas anticoncepcionais, sem orientação médica. Nesse período, aos finais de semana saía com amigas vestida de mulher para ir à porta das boates observar outras travestis. Mas foi após uma conversa com a prima travesti que a entrevistada resolveu refletir mais seriamente sobre a transformação física:

...Foi essa minha prima. Aí ela voltou da Espanha e aí quando ela me viu eu já tava começando a tomar hormônio... eu tomava o anticoncepcional da minha mãe (...) aí ela pegou e falou bem assim: "Ai, vira feminina, porque não sei o que... fica sendo chamado de veado por aí onde vai... por que não muda pra São Paulo e vira logo travesti? Aquela travesti bonita..." Aí eu: "Será? Será que eu tenho coragem?... não sei o quê...” e eu passei um ano criando coragem pra ir pra São Paulo....

Além de temer a violência e a discriminação, Ketlen relembra que a maior dificuldade para decidir ir a São Paulo e assim poder vivenciar com maior liberdade o travestismo foi o temor de deixar sua mãe. A despeito de seus temores, resolveu ir e retornou após um ano e meio bem mais adaptada ao gênero desejado. Embora não tenha dito para a mãe que iria se tornar travesti e se prostituir, durante esse período, quando fazia contato telefônico, dava alguns sinais que fizeram com que a mãe desconfiasse do que estava ocorrendo. Relembra com emoção do dia de seu retorno:

...Eu comecei a chorar quando a aeromoça anunciou que estava sobrevoando o aeroporto internacional (...) Aí eu desci, fui devagarzinho no túnel, sabe: Ai meu Deus, como vai ser?, apreensivo, aquela ansiedade (...) quando eu cheguei no aeroporto, já na porta de desembarque tava ela, o meu irmão mais novo, a minha avó e a minha madrinha. Aí ela não me conheceu. (...) Aí eu saí do desembarque ali, fui num orelhão e liguei no celular dela: "Mãe, eu estou atrás da senhora”. Quando ela olhou pra trás... não teve assim uma reação histérica. Foi lá, me agarrou, me beijou e chorou. Eu chorei, nossa! Eu chorei horrores...
Relata que a fase em que passou pelo processo de transformação física foi difícil, sentia-se sozinha, triste e estava aprendendo a trabalhar em uma profissão arriscada. Os procedimentos para colocar silicone e próteses foram feitos por colegas travestis e eram caros. Sentia medo sempre que se submetia a algum desses procedimentos. Nesse período teve que organizar cuidadosamente as finanças para que pudesse arcar com as despesas da transformação física, do aluguel e do dinheiro que mandava para a mãe.

No que tange à atitude dos familiares após sua transformação, Ketlen foi aceita por todos. Acredita que o fato de ter dois primos homossexuais e uma prima travesti facilitou a compreensão de todos, uma vez que temas relacionados à orientação e identidade de gênero já haviam sido explorados pela família anteriormente. Sua maior preocupação era com a aceitação por parte de sua mãe, todavia relata que esta e seu irmão mais novo a aceitaram e mantém um vínculo bastante afetuoso e próximo consigo. A mãe chegou a conhecer o local onde morava em São Paulo, seu namorado e suas colegas de trabalho. Seus tios e primos também a aceitaram e possui contato frequente e afetuoso com eles. O tema de sua transformação e de sua identidade de gênero nunca foi abordado com o pai e relata quase não ter contato com ele. Atualmente, quando questionada sobre sua identidade de gênero, fica claro que Ketlen não se sente nem como homem e nem como mulher, mas sim como travesti. Além disso, relata sentir-se realizada e feliz com sua identidade:

...Eu me sinto travesti. Eu me sinto travesti... eu não me sinto mulher, nem me sinto homem, eu me sinto travesti. Eu me sinto travesti e gosto de me sentir travesti. (...) Ai eu me sinto realizada, como eu te falei. Eu me sinto realizada, me sinto feliz. (...) Eu me sinto bem. Me sinto bem, me sinto realizada. É... feliz. (...) O que é ser travesti? Ser travesti é ter coragem, força de vontade. Coragem de enfrentar a sociedade toda, o preconceito, a discriminação... e ser travesti tem que... tem que nascer já com aquele dom de ser travesti e eu acho que eu nasci...

Relata não viver sofrimento pelo fato de ser travesti. Quando questionada se vive momentos de conflito ou dúvida em relação à sua identidade de gênero, responde claramente que não, uma vez que se apresenta como travesti, não sendo homem nem mulher. Tal comentário tem ressonância na fala da travesti Marjorie Marchi (Presidente da Associação das Travestis e Transexuais do Rio de Janeiro) no Seminário Nacional Psicologia e Diversidade Sexual: desafios para uma sociedade de direitos (evento promovido pelo Conselho Federal de Psicologia - CFP): "Obviamente, eu digo que travesti não é homem e travesti não é mulher. Travesti é travesti. Travesti é uma identidade única, formulada dentro de uma criação masculina, somada, em determinado momento, a uma criação feminina" (CFP, 2011, p. 74). Ainda nessa fala, destaca que as 
travestis não deveriam ser enquadradas nas questões de diversidade sexual, mas de diversidade de identidade.

Sobre as fases de transição da infância para a adolescência e da adolescência para a idade adulta, em relação aos sentimentos e pensamentos sobre travestir-se, Ketlen sempre quis travestir-se, mas quando criança acreditava que não poderia fazê-lo. Aos poucos, conforme foi crescendo, amadureceu a ideia e foi percebendo que isso seria possível.

...Quando eu era criança, eu achava que eu nunca ia poder ser, sabe. Eu achava que eu nunca ia poder ser. E quando eu cresci eu vi que dava pra poder ser... eu já vi que não ia ser tão difícil. (durante a adolescência) continuou tudo igual, só que eu amadureci mais, né. Eu tinha os pensamentos mais maduros, mais positivos. Agora eu sei que eu vou decidir o que eu quero... ficou mais consolidado...

Acredita que o momento mais decisivo em relação a seus sentimentos sobre sua identidade de gênero foi quando resolveu assumir por quem se sentia atraída sexualmente, considerado um passo importante até conseguir se autodenominar como travesti. Relata que o antigo namorado a via como mulher e não como travesti, por isso não se sentia à vontade para mostrar seu pênis para ele; relata que fazia sexo com calcinha e que sempre era penetrada. Já os parceiros atuais, que são eventuais, a veem como travesti; com estes pratica penetração ativa e passivamente.

Gosta muito de seu corpo em geral e de seu pênis, estabelecendo com esse uma relação de prazer. Não tem desejo de fazer a cirurgia de redesignação sexual e sobre isso, considera um 'pecado'. Quando questionada sobre como se sente ao olhar-se no espelho e observar seu corpo feminino com um pênis, responde que gosta, justamente por ser assim o corpo de uma travesti:

...Eu gosto, eu gosto de ser travesti. O pênis ali faz parte do travesti, faz parte do travesti. (...) Às vezes eu me arrumo, assim pra ir trabalhar e eu fico olhando no espelho e "Ah, eu nasci realmente pra ser travesti". (risos) É assim que eu me vejo...

\section{Vivências sociais}

A entrevistada sempre passou por situações de preconceito e discriminação, mas a fase de maior sofrimento foi no período escolar. Procura ser discreta nos contatos sociais para não passar por situações de constrangimento, mas que frequentemente percebe as pessoas à sua volta fazendo comentários e insinuações maledicentes, piadas e dando risadas. Ketlen justifica que pelo fato de ser muito nervosa, procura não dar atenção a isso para que não acabe discutindo com eles, piorando a situação e passando vergonha. Na época em que fez faculdade, sentiu dificuldade para estabelecer amizades, as pessoas não se aproximavam e Ketlen também não se sentia à vontade para procurá-las. Além disso, notava que faziam comentários sobre ela. Relata que já enfrentou situações de discriminação e cita um exemplo, no qual não foi atendida ao entrar em um estabelecimento no qual vendedores estavam desocupados.

(...) eu fui comprar uma roupa numa loja e tinha vários atendentes atendendo outras pessoas e tinha uns três assim parados, sabe. Aí eu fiquei procurando uma pessoa pra me atender... estava eu e uma amiga minha, e eles fizeram de conta que não tinha ninguém. (...) fui lá na frente da loja, falei com o gerente e falei que não tinha porque eles esnobarem, afinal de contas não tinha muitos clientes dentro da loja e não estavam querendo atender porque a gente era travesti... (...) eu falei isso pra ele: "A gente veio aqui pra comprar, não foi pra pedir nada pra ninguém”. Aí o gerente foi lá, fez um deles atender.

Acredita que embora situações de preconceito e discriminação sejam comuns, a sociedade está se acostumando com a presença de travestis. Ketlen tem amigos homens, mulheres e travestis, mas suas vinculações mais significativas são com os últimos.

\section{Vivências de sua atividade sexual}

Avalia suas práticas sexuais como 'normais', sentindo-se bem. Tem desejo sexual, consegue atingir o orgasmo e tem ereções e ejaculação sem dificuldade. Sente prazer em praticar sexo profissionalmente como em sua vida pessoal. Está satisfeita com sua frequência sexual. No entanto, queixa-se que nos momentos em que está sem desejo costuma sentir dor quando é penetrada. Nesses casos, procura ser rápida, usar maior quantidade de lubrificante, faz sexo oral e questiona o cliente se prefere ser penetrado. Na época em que usava hormônio feminino era frequente ter dificuldade para conseguir ereção, mas conforme o uso de hormônio diminuiu, a disfunção foi resolvida.

Em relação às suas práticas sexuais preferidas, relata que o que mais lhe proporciona satisfação é o sexo anal quando penetrada, no entanto, também sente prazer em penetrar. Profissionalmente, a pedido do cliente, faz sexo com outras travestis, no entanto, nesses casos, não gosta de ser penetrada, apenas de penetrar. Não pratica sexo com mulheres. Na vida pessoal, somente tem atividade com homens.

\section{Saúde física e psíquica}

Não se queixa de nenhum problema físico, atualmente. No passado já teve sífilis e problemas no fígado, procurou ajuda e foi tratada adequadamente. Do ponto 
de vista psicológico, relata que com alguma frequência sente-se triste e enfraquecida emocionalmente pelos problemas cotidianos, especialmente os familiares. Quando a entrevistada tem capacidade para resolver o problema, imediatamente toma as providências para que isso ocorra, mas quando não apresenta esses recursos, sua estratégia é não pensar muito neles e mudar o foco de sua atenção para que não se abata demais. Sente que a ansiedade é uma de suas maiores dificuldades psicológicas. Não tem vontade de procurar ajuda profissional para lidar com essas dificuldades.

(...) problemas me deixam super fraca, super frágil e principalmente assim, os familiares, né. Os da minha família me enfraquecem muito. (...) Ah, eu procuro não me sentir sozinha... eu procuro... eu procuro é... não deixar os problemas vingar na minha cabeça, sabe. (...) nem deixar os problemas entrarem muito na minha cabeça. (...) Eu também procuro ficar conversando, distraindo aí eu não dou mais importância. Mas se eu ficar um dia inteiro sozinha, eu fico louca, me sentindo sozinha, sem ninguém pra conversar...

Na época em que foi morar em São Paulo, abusou de álcool e de outras drogas, especialmente cocaína. O uso de álcool aumentou na época em que terminou o namoro. Atualmente faz uso de bebidas alcoólicas socialmente e de cocaína pouco frequentemente. Parece ter temor de que volte a perder o controle e, por isso, quando faz uso de cocaína sente-se culpada. Novamente, sua estratégia para lidar com os problemas é utilizada: procura não pensar no que fez:

Quando eu me arrependo é pelo fato de cair em depressão... por isso que eu procuro não me arrepender. Eu sou fácil de ficar em depressão... aí eu procuro não me arrepender, porque se eu me arrepender, facinho eu fico em depressão. (...) É, penso que já passou. (...) Fico me sentindo culpada... pelo fato de eu ter usado muito tempo... eu tenho medo de voltar assim, de piorar.

Em relação aos profissionais de saúde, sempre procurou tratamento médico em um centro especializado para profissionais do sexo da rede pública da cidade de São Paulo. Acredita que em função dessa característica da instituição, os profissionais de saúde estavam mais acostumados a atender travestis e fora tratada sempre com muito respeito. No entanto, há que se destacar que essa não é uma prática recorrente nos serviços de saúde, notadamente do setor público (Moscheta, 2011), em que predominam posturas rígidas e de preconceito ou mesmo práticas que integram a necessidade de compreender e respeitar as individualidades e as expressões sexuais, mas, ao mesmo tempo, operando-se a dificuldade de se colocar no lugar do outro e entender a importância de um atendimento à população LGBT que verdadeiramente a inclua no sistema público de saúde como seres de direito. Essa inclusão deve levar em conta a necessidade de que os profissionais dispam-se de seus possíveis preconceitos, atuando na promoção de melhores práticas de saúde a essa população, ouvindo esses clientes, conhecendo suas necessidades, seus corpos, dificuldades e potencialidades.

\section{Discussão}

Ketlen afirma que não se sente como homem, nem como mulher, mas sim como travesti. Optou pela transformação física para se tornar travesti. Assim, não desejava ter o corpo de uma mulher e sim o de uma travesti, ou seja, possuir um pênis em um corpo feminino. Não sofre pelo fato de se sentir como uma travesti, ao contrário, está realizada e feliz por ter alcançado o que almejava e hoje possui o corpo congruente ao modo como se sente e se denomina. Acredita que nasceu com um dom para ser travesti e que não são todas as que o possuem. Não tem o desejo de fazer a cirurgia de redesignação do sexo de nascimento, gosta de seu pênis e este faz parte do 'ser travesti', pela mesma razão sente-se bem ao mirar-se no espelho, mostrando-se congruente com sua identidade de gênero. Em seus relacionamentos eventuais, acredita que os parceiros a percebem como travesti. No entanto, seu antigo namorado a via como mulher.

Os questionamentos sobre a noção de gênero e de sua materialidade e a dicotomia proporcionados por abordagens teóricas advindas do campo da Psicologia, Filosofia, Sociologia e Antropologia (Foucault, 2005; Louro, 2001; Scott, 1990) apresentam-se como possibilidade interessante para se promover reflexões e questionamentos a respeito das travestis. A vivência da participante deste presente estudo incita reflexões a respeito do quão as categorias de gênero masculino e feminino não são capazes de abarcar todas as identidades de gênero. Ketlen se percebe como travesti e não como homem ou como mulher. Conforme Azevedo Jr. (2002), a travesti não apenas rompe com padrões heteronormativos e com a masculinidade, mas cria um novo feminino, um feminino próprio da travesti.

A fenomenologia busca alcançar a essência dos fenômenos não por meio de explicação, mas sim de compreensão. Sendo assim, cumpre explicitar o modo como o ser-no-mundo de Ketlen foi compreendido fenomenologicamente neste estudo. O ser-no-mundo é a estrutura fundamental da experiência humana, ser e mundo, consciência e objeto não podem ser olhados de forma independente, estão indissoluvelmente ligados. O mundo não é compreendido como um conjunto de objetos e pessoas existindo por si mesmos, cada um deles se torna o que é em função da significação dada por quem o percebe. Ser-no-mundo é sempre uma estrutura originária e total, no entanto, pode-se visualizá-la em termos dos diversos aspectos do mundo e das diferentes maneiras do homem existir nele (Forghieri, 1993). 
A existência do homem é originalmente ser-com, ou seja, é por meio das relações com outros seres humanos que atualizamos, compreendemos e desenvolvemos nossas potencialidades humanas, especialmente o amor, a liberdade e a responsabilidade. Essas relações com os outros podem ser denominadas de "mundo humano" (Forghieri, 1993). Na infância, Ketlen viveu uma situação de certo isolamento, tendo contatos sociais bastante restritos. Estabeleceu relação distanciada e permeada pela violência com o pai e de papéis invertidos com a mãe uma vez que esta, em função de sua fragilidade psíquica, parecia necessitar da criança para lhe proteger. Assim, nota-se que o "mundo humano" de Ketlen parece ter proporcionado vivências que dificultaram seu desenvolvimento existencial; por meio da menor exploração de si no mundo, a atualização de suas potencialidades foi prejudicada. As experiências de preconceito social, vividas desde a infância e muito comuns entre travestis (Peres, 2006), parecem ter contribuído para que Ketlen pudesse observar-se diante do "mundo humano", identificando quais eram suas características e de que maneira elas afetavam ou impactavam o entorno.

Em seus diversos contatos posteriores, com o primo com o qual mantinha relações sexuais, com as primas que a travestiam, com os colegas do maracatu, com a prima travesti, dentre outros, Ketlen pode entrar em contato mais franco com o mundo e consigo, proporcionando aumento da conscientização de suas necessidades e potencialidades. Sapienza (2008) aponta que a existência é sempre um poder ser diante de um "para que". Nesse "a fim de que" reside o sentido da vida que deve ser construído no entrelaçamento do ser-no-mundo e as possibilidades construídas por e entre ser e mundo. Vivenciando diversas situações no contato com o "mundo circundante" e com o "mundo humano", o indivíduo vai reconhecendo a si próprio e toma consciência de si, formando o que é chamado de "mundo próprio" (Forghieri, 1993). Este é caracterizado pelas significações que as experiências têm para o indivíduo. No que tange ao "mundo próprio" de Ketlen, há indícios de que possua alguma dificuldade em conscientizar-se de seus sentimentos, apresentando, em determinados momentos, escolhas realizadas a fim de evitar a angústia, prejudicando sua integração existencial. Entretanto, nota-se que a entrevistada se observa como alguém que já passou por inúmeras e grandes dificuldades e que conseguiu e consegue enfrentar os desafios, ainda que utilizando recursos que não necessariamente lhe façam bem ou promovam seu desenvolvimento emocional. Frequentemente se sente fragilizada por problemas cotidianos e que quando não consegue resolvê-los de imediato opta por evitar refletir sobre eles para não piorar sua condição emocional. Ressalta-se, ainda, que relata sentir-se ansiosa e desprezada quando passa um dia inteiro sozinha, sem suas colegas. A presença de perda de controle sobre o álcool e as drogas, de fortes e frequentes sentimentos de tristeza e ansiedade também demonstram sua maior fragilidade existencial. Assim, a entrevistada se observa como alguém forte, que sobreviveu e enfrenta grandes desafios, mas que foge da angústia. Para Heidegger (conforme citado por Dantas, 2011), a angústia não deve ser considerada como uma condição patológica nem deve ser evitada, é antes de tudo um sentimento que determina a condição humana e deve ser vista como uma importante experiência que emerge quando tomamos consciência de nossa condição de seres livres, únicos e mortais. Desse modo, Ketlen, muitas vezes, ao evitar o sentimento de angústia, interrompe a possibilidade de refletir sobre sua existência e mantém pensamentos, sentimentos e condutas rígidos e com pouca mobilidade.

Pode-se dizer que, devido ao ser-no-mundo de Ketlen, esta optou por ser travesti. A liberdade de escolha é algo inerente à existência humana. Existir é se abrir para a percepção e compreensão de tudo o que se apresenta e fazer escolhas. A liberdade é tanto maior quanto for a abertura a essas possibilidades. Isso não significa que não existam limites. Em função da própria materialidade do ser, circunscritores de diversas ordens se impõem. No entanto, mesmo dentro desses limites muitas escolhas podem ser feitas e não há como se saber antecipadamente qual a melhor decisão. Sapienza (2007) explica que a liberdade não é algo a que o homem pode ter acesso, a liberdade é originária, é algo que ele é. Nesse sentido, fazer escolhas comporta lidar com a imprevisibilidade da vida e a ausência de garantias. Existir é poder ser atingido o tempo todo por coisas que nos tocam, constroem ou destroem sentidos previamente elaborados.

Quanto melhor o conhecimento de si e do mundo, maior probabilidade de se fazer escolhas autênticas. Entretanto, o risco da imprevisibilidade é parte de qualquer escolha. Soma-se a isso o fato de que escolher significa abrir-se para algumas possibilidades e renunciar a tantas outras. A perda é inerente à escolha. Kierkegaard (citado por Feijoo, Mattar, Feijoo, Lessa, \& Protasio, 2013), outro filósofo pertencente ao movimento da fenomenologia, aponta que a possibilidade é o elemento do qual a todo o momento nasce a ação do homem em liberdade. A impossibilidade da não-escolha e a inevitabilidade de se viver as consequências das escolhas tomadas lançam o homem na angústia e na indecisão (Feijoo et al., 2013). Em função dessas características de renúncia e riscos, muitos indivíduos optam por adiar as escolhas ao máximo ou tomarem decisões em que se acomodam nas expectativas dos outros, vivendo uma vida inautêntica.

Seria aparentemente mais fácil para a entrevistada escolher viver de acordo com as normas esperadas. Nota-se, inclusive, que Ketlen fez essa tentativa, amasiando-se com uma namorada. No entanto, vivenciou essa experiência como algo que não lhe fazia sentido, incongruente e inautêntico. Sabia que a escolha pela feminilização comportava grandes riscos: rejeição da família e de amigos, dificuldade para se conseguir trabalho, preconceito social, doenças relacionadas ao excesso do uso de hor- 
mônios femininos, dentre outros. A entrevistada resolveu assumir esses riscos e optou pela transformação física. Forghieri (1984) aponta que o existir é anterior ao pensar e por isso é dele que se deve partir para encontrar a verdade. Parece que foi assim que a entrevistada intuitivamente procedeu. Por mais que vivesse no modo de existir racional, que pesassem os prós e contras de sua decisão, que avaliasse cuidadosamente a realidade externa, foram as vivências de seu ser-no-mundo que apontaram para a sua verdade e para a "coragem" de se transformar, correspondendo à sua predestinação-no-mundo: nascera com o "dom" de ser travesti, nascera para ser travesti. O olhar do pesquisador, nesse sentido, deve ser o de acolher essa escuta e compreendê-la no percurso de vida da participante, com destaque para a potencialização de seus recursos e estratégias de enfrentamento do cotidiano.

\section{Considerações finais}

Por fim, cumpre mencionar que o presente estudo não pretende trazer conclusões, orientações ou certezas sobre o assunto, apenas tenciona apresentar reflexões elaboradas em função do contato com a literatura científica e com a própria participante e lançar luz sobre um tema tão importante e ainda pouco compreendido. As travestis constituem uma categoria marginalizada em nossa sociedade, de modo que a compreensão sobre seus percursos desenvolvimentais, aqui explicitados a partir das suas vivências, pode contribuir para uma análise menos estereotipada e normatizadora. Buscar o modo como a travesti significa as suas experiências também mostrou-se uma estratégia metodológica importante no sentido de valorizar o olhar da protagonista do processo, em contraposição a explicações científicas vindas “de fora” e, por vezes, que recuperam uma tradição positivista marcada por um saber externo e que vê pesquisador e objeto como entes distanciados. A construção de um contexto de escuta autêntica possibilitou que fosse construída uma narrativa densa, detalhada e que ofereceu suporte para uma discussão sobre o que é “ser travesti” para além do já-dito ou de nosologias presentes em diversos estudos em circulação. Designar-se, perceber-se e reconhecer-se como travesti, pelas falas da participante, ultrapassaria as definições existentes e abriria espaço para novas considerações que desafiam os pesquisadores: o que seria "nascer já com aquele dom”? Esse dom estaria cravado no existir de Ketlen, sendo que a escuta atenta ao caso nos leva a concluir que há espaço, nessa definição, para a complexidade que atravessa suas experiências de vida nos diversos domínios. Essa escuta, portanto, aproxima pesquisadora e pesquisada, promovendo a assunção de diversos sentidos nem sempre balizados e reconhecíveis nos estudos da área.

Assim, por meio desse relato, objetivou-se realizar uma aproximação qualitativa das vivências, sentimentos e experiências de uma travesti, que compõe uma população sabi- damente invisível aos olhos da sociedade. As vivências de Ketlen assemelham-se a tantas outras e podem ser deflagradoras de percursos de desenvolvimento que merecem a atenção dos pesquisadores para melhor compreensão sobre esses trajetos e caminhos. A excessiva preocupação com a prevenção de doenças nessa população, embora possua uma inquestionável importância em termos de políticas públicas de saúde, não pode obscurecer uma atuação em saúde voltada à consideração das travestis como pessoas em desenvolvimento, com trajetórias, dúvidas, questionamentos, subjetividades e potencialidades que devem ser reconhecidas e incorporadas ao processo de escuta e de atenção em saúde. Perspectivas de gênero que possam abarcar essas vicissitudes ao invés de enquadrá-las, patologizá-las e/ou diagnosticá-las podem e devem contribuir para a assunção de posturas mais sensíveis por parte de pesquisadores, profissionais de saúde e familiares envolvidos com a complexidade da diversidade sexual.

\section{Referências}

Amaral, M. S., Silva, T. C., Cruz, K. O., \& Toneli, M. J. F. (2014). "Do travestismo às travestilidades": Uma revisão do discurso acadêmico no Brasil entre 2001-2010. Psicologia e Sociedade, 26 (2), 301-311.

Araújo Júnior J. C. (2006). A metamorfose encarnada: Traves-timento em Londrina. Dissertação de Mestrado, Instituto de Filosofia e Ciências Humanas, Universidade Estadual de Campinas, Campinas, SP.

Augras, M. (1986). O ser da compreensão: Fenomenologia da situação de psicodiagnóstico. Rio de Janeiro: Vozes.

Azevedo Jr., J. (2002). Travesti: O homem borboleta - uma compreensão fenomenológica sobre o transvestismo. Dissertação de Mestrado, Programa de Pós-Graduação em Psicologia, Pontifícia Universidade Católica do Rio Grande do Sul, Porto Alegre.

Azevedo, R. N. (2009). Travestis: Um estudo de caso. Monografia de conclusão de curso, Faculdade de Medicina da Universidade de São Paulo, São Paulo.

Azevedo, R. N., Spizzirri, G., \& Scorsolini-Comin, F. (2014). Histórias de vida e vivências familiares de jovens travestis. Em F. Scorsolini-Comin, L. V. Souza, \& S. M. Barroso (Orgs.), Práticas em Psicologia: Saúde, família e comunidade (p. 169-196). Uberaba: Editora da Universidade Federal do Triângulo Mineiro.

Butler, J. (2002). Críticamente subversiva. Em R. M. M. Jimenez, Sexualidades transgresoras: Una antología de estudios queer (p. 55-81). Barcelona: Icária Editorial.

Ceglian C. M. P., \& Lyons, N. N. (2004). Gender type and comfort with cross-dressers. Sex-Roles, 50 (7/8), 539-546.

Chidiac, M. T. V., \& Oltramari, L. C. (2004). Ser e estar drag queen: Um estudo sobre a configuração da identidade queer. Estudos de Psicologia, 9 (3), 471-478. 
Conselho Federal de Psicologia [CFP] (2011). Psicologia e diversidade sexual: Desafios para uma sociedade de direitos. Brasília: Autor.

Dantas, J. B. (2011). Angústia e existência na contemporaneidade. Rio de Janeiro: Rubio.

Dartigues, A. (2005). O que é a fenomenologia? (10. ed.). São Paulo: Centauro.

Docter, R. F., \& Price, V. (1997). Transvestism: A survey of 1032 cross-dressers. Archives of Sexual Behavior, 26 (6), 589-605.

Duque, T. (2012). Reflexões teóricas, políticas e metodológicas sobre um morrer, virar e nascer travesti na adolescência. Revista de Estudos Feministas, 20 (2), 489-500.

Feijoo, A. M. L. C., Mattar, C. M., Feijoo, E. L., Lessa, M. B. M. F., \& Protasio, M. M. (2013). O pensamento de Kierkegaard e a clínica psicológica. Rio de Janeiro: IFEN.

Forghieri, Y. C. (1984). Fenomenologia e psicologia. São Paulo: Cortez.

Forghieri, Y. C. (1993). Psicologia fenomenológica: Fundamentos, método e pesquisas. São Paulo: Pioneira.

Foucault, M. (2005). História da sexualidade 1: A vontade de saber. São Paulo: Graal.

Galli, R. A. (2013). Roteiros sexuais de transexuais e travestis e seus modos de envolvimento sexual. Dissertação de mestrado, Faculdade de Filosofia, Ciências e Letras de Ribeirão Preto, Universidade de São Paulo, Ribeirão Preto, SP.

Leite Jr., J. (2011). Nossos corpos também mudam: A invenção das categorias "travesti" e "transexual" no discurso científico. São Paulo: Annablume.

Louro, G. L. (2001). Teoria queer: Uma política pós identitária para a educação. Revista de Estudos Feministas, 2 (9), 541-553.

Louro, G. L. (2009). Heteronormatividade e homofobia. Em R. D. Junqueira (Org.), Diversidade sexual na educação: Problematizações sobre a homofobia nas escolas (p. 85-94). Brasília: Ministério da Educação, Secretaria de Educação Continuada, Alfabetização e Diversidade, UNESCO.

Martins, J., \& Bicudo, M. A. V. (2005). A pesquisa qualitativa em psicologia: Fundamentos e recursos básicos (5. ed.). São Paulo: Centauro.

Miskolci, R., \& Pelúcio, L. (2007). Fora do sujeito e fora do lugar: Reflexões sobre performatividade a partir de uma etnografia entre travestis que se prostituem. Gênero, 7, 257-267.

Moraes, F. (2009). Instrumentalização social contra estigmas e preconceitos. Recuperado de http://goo.gl/JiRbD

Moscheta, M. S. (2011). DemocraciaS. Saúde \& Transformação Social, 1 (2), 1-3.

Pelúcio, L. (2005). Na noite nem todos os gatos são pardos: Notas sobre a prostituição travesti. Cadernos Pagu, 25, 217-248.

Peres, R. S., \& Santos, M. A. (2005). Considerações gerais e orientações práticas acerca do emprego de estudos de caso na pesquisa científica em Psicologia. Interações, 20 (10), 109-126.
Peres, W. S. (2006). Subjetividades das Travestis Brasileiras: Interfaces entre estigmas e construção da cidadania. Em Seminário Internacional Fazendo Gênero 7: Gênero e Preconceitos (p. 1-8). Recuperado em 9 de outubro de 2012 de http://goo.gl/cDk34.

Peres, W. S. (2009). Cenas de exclusões anunciadas: Travestis, transexuais, transgêneros e a escola brasileira. Em R. D. Junqueira (Org.), Diversidade sexual na educação: Problematizações sobre a homofobia nas escolas (p. 235-263). Brasília: Ministério da Educação, Secretaria de Educação Continuada, Alfabetização e Diversidade, UNESCO.

Peres, W. S., \& Toledo, L. G. (2011). Travestis, transexuais e transgêneros: Novas imagens e expressões da subjetividade. Em Conselho Regional de Psicologia da $6^{\text {a }}$ Região (Org.), Psicologia e diversidade sexual: Cadernos temáticos, 11, 78-89. Recuperado de www.crpsp.org.br.

Peres, W. S. (2012). Travestilidades nômades: A explosão dos binarismos e a emergência queering. Revista de Estudos Feministas, 20 (2), 539-547.

Sapienza, B. T. (2007). Do desabrigo à confiança: Daseinanálise e terapia. São Paulo. Escuta.

Sapienza, B. T. (2008). Conversa sobre terapia. São Paulo: Educ Paulus.

Scott, J. (1990). Gênero: Uma categoria útil de análise histórica. Educação \& Realidade, 16 (2), 5-22.

Spizzirri, G., Azevedo, R. N., \& Abdo, C. H. N. (2011). Traves-tismo de duplo papel ou bivalente: Considerações gerais. Diagnóstico \& Tratamento, 16 (1), 29-32.

Roberta Noronha Azevedo - Psicóloga e mestranda em Psicologia pela Faculdade de Filosofia, Ciências e Letras de Ribeirão Preto da Universidade de São Paulo. Especialista em Sexualidade Humana pela Faculdade de Medicina da Universidade de São Paulo. E-mail: rn_azevedo@yahoo.com.br

Fabio Scorsolini-Comin - Doutor em Psicologia pela Universidade de São Paulo e docente do Programa de Pós-graduação em Psicologia da Universidade Federal do Triângulo Mineiro. E-mail:fabioscorsolini@gmail.com

Giancarlo Spizzirri - Psiquiatra e Doutorando em Medicina pelo Instituto de Psiquiatria da Faculdade de Medicina da Universidade de São Paulo. Médico do Programa de Estudos em Sexualidade (ProSex) do Instituto de Psiquiatria do Hospital das Clínicas.

Recebido em 18.02.2014 Primeira Decisão Editorial em 25.09.2014 Aceito em 25.02.2015 